\title{
Hepatocellular Carcinoma in Korea Between 2008 and 2011: an Analysis of Korean Nationwide Cancer Registry
}

\author{
Jun Sik Yoon ${ }^{1 *}$, Han Ah Lee ${ }^{2^{*}}$, Jun Yong Park ${ }^{3}$, Bo Hyun Kim ${ }^{4}$, In Joon Lee ${ }^{5}$, Young Eun Chon ${ }^{6}$, Suk Kyun Hong ${ }^{7}$, \\ Dong Hyeon Lee ${ }^{8}$, Hyun-Joo Kong ${ }^{9}$, Young-Joo Won', Eunyang Kim ${ }^{9}$, Jeong-Hoon Lee ${ }^{10}$ \\ 'Department of Internal Medicine, Busan Paik Hospital, Inje University College of Medicine, Busan; ${ }^{2}$ Department of Internal Medicine, \\ Korea University College of Medicine, Seoul; ${ }^{3}$ Department of Internal Medicine, Yonsei University College of Medicine, Seoul; ${ }^{4}$ Center for \\ Liver Cancer, Research Institute and Hospital, Goyang; ${ }^{5}$ Department of Radiology, National Cancer Center, Goyang; ${ }^{6}$ Department of \\ Internal Medicine, CHA Bundang Medical Center, CHA University, Seongnam; 'Department of Surgery, Seoul National University \\ College of Medicine, Seoul; ${ }^{8}$ Department of Internal Medicine, Seoul Metropolitan Government Seoul National University Boramae \\ Medical Center, Seoul; ${ }^{9}$ Cancer Registration and Statistic Branch, National Cancer Control Institute, National Cancer Center, Goyang; \\ ${ }^{10}$ Department of Internal Medicine and Liver Research Institute, Seoul National University College of Medicine, Seoul, Korea
}

Received Dec. 31, 2019

Revised Feb. 6, 2020

Accepted Feb. 7,2020
Backgrounds/Aims: Backgrounds/Aims: In Korea, hepatocellular carcinoma (HCC) is the sixth most common cancer and results in the second-highest cancer death rate among all cancers. We aimed to describe the characteristics of patients who were newly diagnosed with HCC in Korea between 2008 and 2011.

Methods: The Korean Primary Liver Cancer Registry (KPLCR) is a random sample consisting of approximately $15 \%$ of patients with newly diagnosed primary liver cancer registered in the Korean Central Cancer Registry. We investigated the baseline characteristics, treatment modalities, and overall survival (OS) of patients with HCC registered in the KPLCR between 2008 and 2011.

Results: A total of 6,083 patients were histologically or radiologically diagnosed with HCC. The hepatitis $B$ virus was the predominant $\mathrm{HCC}$ etiology (72.0\%). According to the Barcelona Clinic Liver Cancer (BCLC) staging system, stages 0, A, B, C, and D accounted for 8.6\%, 39.7\%, $11.5 \%, 33.8 \%$, and $6.9 \%$, respectively. Transarterial therapy (41.7\%) was the most commonly performed initial treatment, followed by best supportive care $(21.7 \%)$, surgical resection (16.7\%), and local ablation therapies (10.6\%). The overall rate of adherence to the BCLC treatment guideline was only $37.7 \%$. The $1-, 3-$, and 5 -year OS rates were $65.6 \%, 46.2 \%$, and $36.8 \%$, respectively.

Conclusions: Between 2008 and 2011, approximately half of patients with HCC (48.3\%) were candidates for curative treatment (BCLC stage 0 or A), but one-third of patients (33.8\%) had advanced HCC (BCLC stage C). Transarterial therapy was the most commonly conducted initial treatment and the 5 -year OS rate was 36.8\% in this period. (J Liver Cancer 2020;20:41-52)

Keywords: Hepatocellular carcinoma; Epidemiology; Overall survival; Hepatitis B; Korea

\section{Corresponding author : Jeong-Hoon Lee}

Department of Internal Medicine, Seoul National University Hospital, 101 Daehak-ro, Jongno-gu, Seoul 03080, Korea

Tel. +82-2-2072-2228, Fax. +82-2-743-6701

E-mail; JHLeeMD@snu.ac.kr

https://orcid.org/0000-0002-0315-2080

\section{INTRODUCTION}

Primary liver cancer is the sixth most common cancer and results in the second-highest cancer death rate among all

* The first two authors contributed equally to this study. 
cancers in Korea. ${ }^{1-3}$ Hepatocellular carcinoma (HCC) accounts for more than $80-90 \%$ of primary liver cancer cases. ${ }^{4,5}$ Korea is a hepatitis B virus (HBV)-endemic area, and chronic hepatitis B accounts for $62-75 \%$ of HCC etiology. ${ }^{6-8}$ As the prevalence of chronic hepatitis $B$ increases with age, the incidence and mortality rates of HCC are highest among the economically active working-age (40-59 years) group. ${ }^{9}$ Therefore, HCC imposes the highest economic burden among all cancers in Korea. ${ }^{10}$ To reduce the development of HCC and improve the prognosis of patients with HCC, a large number of studies regarding the management of HCC are published every year in Korea. Accurate information on the characteristics and overall survival (OS) of patients with HCC is essential to establish an optimal strategy for managing HCC. However, there has been a lack of large-scale, nationwide data to represent the typical characteristics of Korean patients with HCC. Therefore, we aimed to describe the baseline characteristics, treatment modalities, and OS of patients newly diagnosed with HCC utilizing a nationwide population-based cancer registry in Korea.

\section{METHODS}

\section{Study population}

The study population was selected from the patients registered in the Korean Primary Liver Cancer Registry (KPLCR). The KPLCR is a random sample consisting of approximately $15 \%$ of patients newly diagnosed with primary liver cancer registered in the Korean Central Cancer Registry (KCCR), which is a nationwide cancer registry and includes more than 95\% of all cancer cases in Korea. The patients in the KPLCR were selected from the KCCR using a probability proportional to size method and stratification by region in a given year. Therefore, the KPLCR is a representative group of patients with newly diagnosed HCC in Korea. We investigated the patients registered in the KPLCR between 2008 and 2011. All patients included in the study were diagnosed with HCC histologically or radiologically. ${ }^{11,12}$ We also performed survival analyses among patients who underwent the initial treatment within 120 days from their diagnosis or received best supportive care (designated as the treatment group). Because the median doubling time of an HCC lesion is approximately 117 days, ${ }^{13}$ patients who received the initial treatment more than 120 days after their diagnosis date were likely to receive the treatment at a more advanced tumor stage than their initial tumor stage. Therefore, we excluded patients who received treatment more than 120 days after the initial date of diagnosis in the survival analyses. Because the KPLCR data in our study were collected as part of the KCCR in accordance with the Cancer Control Act, the need for institutional review board approval was waived.

\section{Basic statistics}

Individual information about the study population was obtained from medical records at the hospital where the diagnosis was made. KCCR-trained registry recorders in each hospital investigated the medical records. Data were extracted using a standardized case record form and validated by statisticians at the KCCR and the KPLCR. Collected data included not only baseline characteristics such as demographic, laboratory, and tumor variables, but also treatment modalities and OS of the patients. All of the tumor variables were assessed by diagnostic imaging such as dynamic computed tomography (CT) or magnetic resonance imaging (MRI). Both the modified Union for International Cancer Control (mUICC) staging system ${ }^{14,15}$ and the Barcelona Clinic Liver Cancer (BCLC) staging system ${ }^{16}$ were adapted as staging systems for HCC.

\section{Overall survival}

The OS was measured from the date of the HCC diagnosis until death from any cause. The date of the HCC diagnosis was defined as the date when the patient underwent dynamic CT or MRI for the HCC diagnosis. Death certificate data were obtained from national statistical data collected by the Korean Ministry of Government Administration and Home Affairs. Individual data of patients' vital statistics were identified using 13-digit unique resident registration numbers issued to all Koreans. Final data cut-off date was December 31, 
2017. The OS rates were obtained from the patients with HCC classified according to their baseline characteristics. The survival curves were also constructed according to the subgroups classified by the underlying liver functions and tumor stages using the Kaplan-Meier method. The survival differences were compared by the log-rank test. The survival analyses were conducted using $\mathrm{R}$ version 3.5.2 (http://www. r-project.org) with $P<0.05$ considered statistically significant.

\section{RESULTS}

\section{Study population}

Between 2008 and 2011, 6,146 patients were registered in the KPLCR. Of these, 63 patients were histologically diagnosed with other malignancies and excluded from the study. Therefore, 6,083 patients were selected as the study population. Among the patients with HCC, we excluded 1) patients who received their initial treatment more than 120 days from the date of diagnosis $(\mathrm{n}=103)$ and 2) patients lacking information on treatment modalities $(\mathrm{n}=6)$. As a result, 5,974 patients were selected as the treatment group. The treatment group consisted of patients who received active treatment $(\mathrm{n}=4,679)$ and those who received best supportive care $(n=1,295)$. The flow diagram of the study population is shown in Supplementary Fig. 1.

\section{Basic statistics}

\section{1) Baseline characteristics}

The baseline characteristics of the study population $(n=6,083)$ are presented in Table 1 . The median age of the study population was 59 years (range, 2-98 years), and the majority were male $(78.7 \%)$. HBV was the predominant etiology (72.0\%), followed by alcohol (13.4\%), hepatitis C virus $(12.0 \%)$, and others $(2.5 \%)$. When the underlying liver function was estimated according to Child-Turcotte-Pugh (CTP) class, $71.0 \%, 23.7 \%$, and $5.1 \%$ of patients were in CTP classes $\mathrm{A}, \mathrm{B}$, and $\mathrm{C}$, respectively. According to the mUICC staging system, stage II (37.5\%) was the most common, followed by stage III (26.1\%), stage I (14.1\%), stage IV-A (12.3\%), and stage IV-B (9.9\%). According to the BCLC staging system, stage A (39.7\%) was the most common, followed by stage $\mathrm{C}$ $(33.8 \%)$, stage B $(11.5 \%)$, stage $0(8.6 \%)$, and stage D $(6.9 \%)$. A solitary tumor was observed in $61.5 \%$ of the patients, and the median maximal diameter of tumors was 3.0 $\mathrm{cm}$. Vascular invasions to the portal vein and hepatic vein were observed in $24.3 \%$ and $5.6 \%$ of the patients, respectively. Lymph node metastasis and distant metastasis were observed in $7.1 \%$ and $9.9 \%$ of patients, respectively.

\section{2) Initial treatment modality}

As shown in Table 2, of the patients in the treatment group $(\mathrm{n}=5,974), 17.6 \%$ underwent surgical therapies (i.e., surgical resection and liver transplantation), 54.2\% underwent locoregional therapies (i.e., local ablation therapy, transarterial therapy, and a combination of local ablation and transarterial therapy), $3.7 \%$ underwent systemic therapy, $1.0 \%$ underwent external beam radiation therapy, $21.7 \%$ underwent best supportive care, and $1.7 \%$ underwent miscellaneous therapies (i.e., combination therapies other than transarterial therapy and local ablation therapy). Transarterial therapy (41.7\%) was the most commonly performed therapy or procedure as an initial treatment, followed by best supportive care (21.7\%), surgical resection (16.7\%), and local ablation therapies (10.6\%). The majority of local ablation therapies was radiofrequency ablation (594/636, 99.4\%). Among the transarterial therapies, conventional transarterial chemoembolization with or without a gelatin sponge was the most frequently performed procedure $(2,407 / 2,493$, $96.6 \%)$. Sorafenib was the most commonly used agent for systemic therapy (175/224, 78.1\%).

The treatment modalities used at each BCLC stage are presented in Fig. 1. For BCLC stage 0 or A, transarterial therapy $(41.8 \%)$ was the most commonly conducted initial treatment, followed by surgical therapy (27.3\%) and local ablation therapy (19.4\%)., and it was for BCLC stages B and C as well. BCLC stages B and C. Although systemic therapy is a standard treatment modality of BCLC stage $\mathrm{C}$, it was conducted in only $9.5 \%$ of patients with BCLC stage C. For BCLC stage D, best supportive care was the most commonly conducted treatment modality. We show the rates of adherence to the BCLC treatment guideline according to each 
BCLC stage in Supplementary Table 1. The overall adherence rate of the total study population was only $37.4 \%$. We also show the treatment modalities according to each mUICC stage in Supplementary Fig. 2. Transarterial therapy was the most commonly conducted initial treatment for mUICC stages I-III. For mUICC stage IV, best supportive care was the most commonly conducted treatment modality.

\section{3) Baseline characteristics according to treatment mo- dalities}

The baseline characteristics of the patients treated with surgical therapies including surgical resection $(n=998)$ and liver transplantation $(\mathrm{n}=55)$ are presented in Supplementary Table 2. Most patients treated with surgical resection had a good performance status of 0 or 1 (99.4\%) and well-preserved liver function of CTP class A (95.4\%). Of the patients treated with surgical resection, $21.2 \%, 53.6 \%$, and $25.2 \%$ had a maximal tumor diameter measuring $\leq 2,2-5$, and $\geq 5 \mathrm{~cm}$, respectively; $85.9 \%$ of these tumors were solitary. In the case of liver transplantation, more than half of the patients had poor liver function of CTP class B or C (53.8\%) and multiple tumors $(50.9 \%)$.

The baseline characteristics of the patients treated with locoregional therapies including local ablation therapy $(\mathrm{n}=636)$, transarterial therapy $(\mathrm{n}=2,493)$, and a combination of local ablation and transarterial therapy $(\mathrm{n}=108)$ are presented in Supplementary Table 3. Most patients had a good performance status of 0 or 1 ( $98.0 \%, 96.4 \%$, and $98.8 \%$ of patients treated with local ablation therapy, transarterial therapy, and combination therapy, respectively) and wellpreserved liver function classified as CTP class A $(80.8 \%$, $75.1 \%$, and $78.8 \%$ of patients treated with local ablation therapy, transarterial therapy, and combination therapy, respectively). The proportion of patients with multiple tumors and the median maximal diameter of tumors were highest in patients treated with transarterial therapy $(43.1 \%$ and 3.0 $\mathrm{cm})$, followed by combination therapy $(32.7 \%$ and $2.0 \mathrm{~cm})$ and local ablation therapy $(15.6 \%$ and $1.9 \mathrm{~cm})$.

The baseline characteristics of the patients treated with other therapies, including systemic therapy ( $\mathrm{n}=224)$, external beam radiation therapy $(n=61)$, best supportive care
Table 1. Baseline characteristics of the study population $(n=6,083)$

\begin{tabular}{|c|c|}
\hline Variable & Value \\
\hline \multicolumn{2}{|l|}{ Demographic variable } \\
\hline Age (years) & $59.0(51.0-68.0)$ \\
\hline Sex (male) & $4,790(78.7)$ \\
\hline Diabetes & $1,401(23.0)$ \\
\hline Hypertension & $1,808(29.7)$ \\
\hline Body mass index $\left(\mathrm{kg} / \mathrm{m}^{2}\right)$ & $23.7(21.7-25.8)$ \\
\hline Smoking & $2,657(43.7)$ \\
\hline \multicolumn{2}{|c|}{ Etiology $(n=5,291$, missing values=792) } \\
\hline $\mathrm{HBV}^{*}$ & $3,810(72.0)$ \\
\hline $\mathrm{HCV}$ & $636(12.0)$ \\
\hline Alcohol & $711(13.4)$ \\
\hline Others & $134(2.5)$ \\
\hline \multicolumn{2}{|c|}{$\begin{array}{l}\text { Performance status }{ }^{\dagger}(\mathrm{n}=4,162, \text { missing } \\
\text { values }=1,921)\end{array}$} \\
\hline 0 & $3,231(77.6)$ \\
\hline 1 & $641(15.4)$ \\
\hline 2 & $159(3.8)$ \\
\hline 3 & $74(1.8)$ \\
\hline 4 & $57(1.4)$ \\
\hline \multicolumn{2}{|c|}{ Ascites $(n=6,006$, missing values $=77)$} \\
\hline None & $4,509(75.1)$ \\
\hline Mild & $964(16.1)$ \\
\hline Moderate to severe & $533(8.9)$ \\
\hline \multicolumn{2}{|l|}{$\begin{array}{l}\text { Encephalopathy ( } n=6,045 \text {, missing } \\
\text { values=38) }\end{array}$} \\
\hline None & $5,894(97.5)$ \\
\hline Mild to moderate (grade 1 or 2 ) & $119(2.0)$ \\
\hline Severe (grade 3 or 4 ) & $32(0.5)$ \\
\hline \multicolumn{2}{|l|}{ Laboratory variables } \\
\hline Total bilirubin (mg/dL) & $1.0(0.70-1.60)$ \\
\hline Serum albumin (g/dL) & $3.8(3.2-4.2)$ \\
\hline Alanine aminotransferase (IU/L) & $38.0(24.0-61.0)$ \\
\hline Platelet count $\left(10^{9} / \mathrm{L}\right)$ & $139.0(95.0-199.0)$ \\
\hline Prothrombin time (INR) & $1.11(1.04-1.22)$ \\
\hline Creatinine (mg/dL) & $0.90(0.74-1.00)$ \\
\hline Sodium (mmol/L) & $139.0(136.0-141.0)$ \\
\hline Glucose (mg/dL) & $109.0(94.0-139.0)$ \\
\hline Total cholesterol (mg/dL) & $155.0(130.0-182.0)$ \\
\hline Alpha-fetoprotein (ng/mL) & $47.4(7.3-785.0)$ \\
\hline PIVKA-II (mAU/mL) & $144.5(30.0-1,373.0)$ \\
\hline
\end{tabular}


Table 1. Continued

\begin{tabular}{|c|c|}
\hline Variable & Value \\
\hline \multicolumn{2}{|c|}{$\begin{array}{l}\text { Child-Turcotte-Pugh class }(n=5,719 \text {, } \\
\text { missing values }=364)\end{array}$} \\
\hline A & $4,063(71.0)$ \\
\hline$B$ & $1,362(23.8)$ \\
\hline C & $294(5.1)$ \\
\hline MELD score & $8.6(7.3-11.1)$ \\
\hline MELD-Na score & $10.1(8.0-13.8)$ \\
\hline \multicolumn{2}{|l|}{ Tumor variable } \\
\hline \multicolumn{2}{|l|}{$\begin{array}{l}\text { Tumor number }(n=6,061 \text {, missing } \\
\text { values }=22 \text { ) }\end{array}$} \\
\hline 1 & $3,725(61.5)$ \\
\hline 2 & $826(13.6)$ \\
\hline 3 & $247(4.1)$ \\
\hline 4 & $95(1.6)$ \\
\hline$\geq 5$ & $1,168(19.3)$ \\
\hline Maximal tumor diameter $(\mathrm{cm})$ & $3.0(2.0-5.4)$ \\
\hline Portal vein invasion & $1,477(24.3)$ \\
\hline Hepatic vein invasion & $339(5.6)$ \\
\hline Bile duct invasion & $159(2.6)$ \\
\hline Lymph node metastasis & $431(7.1)$ \\
\hline Distant metastasis & $602(9.9)$ \\
\hline \multicolumn{2}{|c|}{$\begin{array}{l}\text { Modified UICC stage }(n=6,045, \text { missing } \\
\text { values }=38)\end{array}$} \\
\hline Stage I & $854(14.1)$ \\
\hline Stage II & $2,267(37.5)$ \\
\hline Stage III & $1,577(26.1)$ \\
\hline Stage IV-A & 746 (12.3) \\
\hline Stage IV-B & $601(9.9)$ \\
\hline \multicolumn{2}{|c|}{ BCLC stage $(n=5,697$, missing values $=386)$} \\
\hline 0 & $489(8.6)$ \\
\hline A & $2,260(39.7)$ \\
\hline B & $658(11.5)$ \\
\hline C & $1,923(33.8)$ \\
\hline D & $391(6.9)$ \\
\hline
\end{tabular}

Values are presented as median (interquartile range) or number (\%). HBV, hepatitis B virus; HCV, hepatitis C virus; INR, international normalized ratio; PIVKA-II, protein induced by vitamin K absence-II; MELD, model for end-stage liver disease; UICC, Union for International Cancer Control; BCLC, Barcelona Clinic Liver Cancer.

"Patients co-infected with HBV and HCV $(n=87)$ were also included; ${ }^{\dagger}$ Performance status was defined as follows: 0, fully active without symptoms; 1 , ambulatory with symptoms; 2 , bedridden $<50 \%$ of the time; 3 , bedridden $>50 \%$ of the time but capable of self-care; 4 , bedridden $100 \%$ of the time and incapable of self-care.
Table 2. The initial treatment modality of the patients in the treatment group $(n=5,974)$

\begin{tabular}{lc}
\hline Treatment modality & Value \\
\hline Surgical resection & $998(16.7)$ \\
Liver transplantation & $55(0.9)$ \\
Local ablation therapy & $636(10.6)$ \\
RFA & 594 \\
PEI & 37 \\
Other local ablation & 5 \\
Transarterial therapy & $2,493(41.7)$ \\
Conventional TACE & 2,407 \\
TACE with drug-eluting beads & 64 \\
Radioembolization & 7 \\
HAIC & 82 \\
Combination therapy ${ }^{*}$ & $108(1.8)$ \\
\hline Systemic therapy & $224(3.7)$ \\
Sorafenib & 175 \\
Other systemic agents & 77 \\
\hline External beam radiation therapy & $61(1.0)$ \\
\hline Best supportive care & $1,295(21.7)$ \\
\hline Miscellaneous therapies ${ }^{\dagger}$ & $104(1.7)$ \\
\hline Val are presented as number $(\%)$
\end{tabular}

Values are presented as number (\%) unless otherwise indicated.

RFA, radiofrequency ablation; PEl, percutaneous ethanol injection; TACE, transarterial chemoembolization; HAIC, hepatic arterial infusional chemotherapy.

${ }^{*}$ Combination therapy is defined as the combined treatment of local ablation therapy and transarterial therapy; ${ }^{\dagger}$ Miscellaneous therapies are defined as unclassifiable treatment modalities (i.e., combination therapies other than transarterial therapy and local ablation therapy).

$(\mathrm{n}=1,295)$, and miscellaneous therapies $(\mathrm{n}=104)$, are presented in Supplementary Table 4 . The proportions of patients with a poor performance status $(\geq 2)$ and poor liver function (CTP class B or C) were the highest in patients treated with best supportive care $(23.6 \%$ and $58.0 \%)$, followed by external beam radiation therapy $(13.2 \%$ and $53.4 \%)$ and systemic therapy (7.9\% and $39.2 \%)$. The proportion of patients with multiple tumors and the median maximal diameter of tumors were highest in patients treated with systemic therapy $(67.0 \%$ and $7.0 \mathrm{~cm})$, followed by best supportive care $(59.1 \%$ and $6.0 \mathrm{~cm})$ and external beam radiation therapy $(47.5 \%$ and $4.2 \mathrm{~cm})$. 


\section{Overall survival}

The OS rates of the patients in the HCC group classified according to their baseline characteristics and their initial treatment modalities are presented in Table 3. The 1-, 3-, and 5 -year OS rates for the entire study population were $65.6 \%, 46.2 \%$, and $36.8 \%$, respectively (Fig. 2A). All of the variables included in the formula of the CTP class (presence of ascites and hepatic encephalopathy, the serum levels of bilirubin and albumin, and prothrombin time) showed a good discriminatory performance on the prognosis of pa- tients with HCC (all log-rank $P<0.001$; Supplementary Fig. 3). All of the survival curves according to CTP class (Fig. 2B), mUICC stage (Fig. 2C), and BLCL stage (Fig. 2D) showed significant survival differences (all log-rank $P<0.001$ ). We also performed post hoc analyses of log-rank tests for multiple comparisons between each survival curve. We found significant survival differences among all CTP classes and all vHCC stages (all pairwise comparisons of log-rank $P<0.001$ ).

\section{Total}

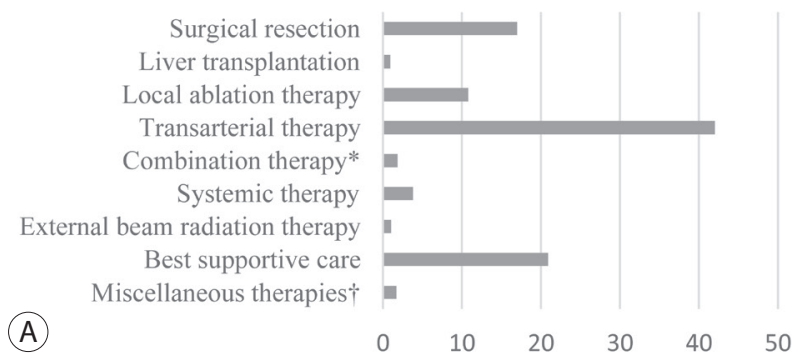

\section{BCLC Stage A}

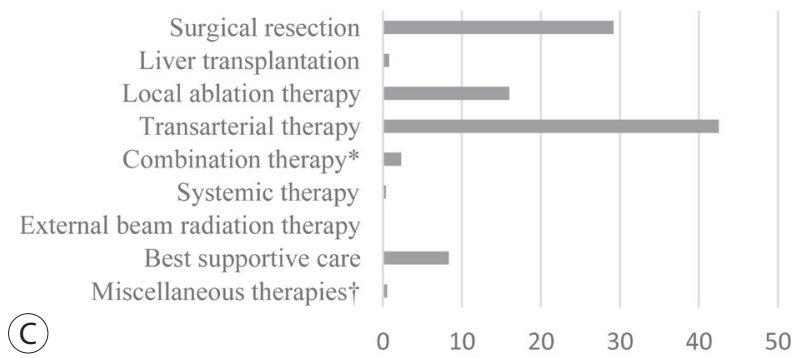

\section{BCLC Stage C}

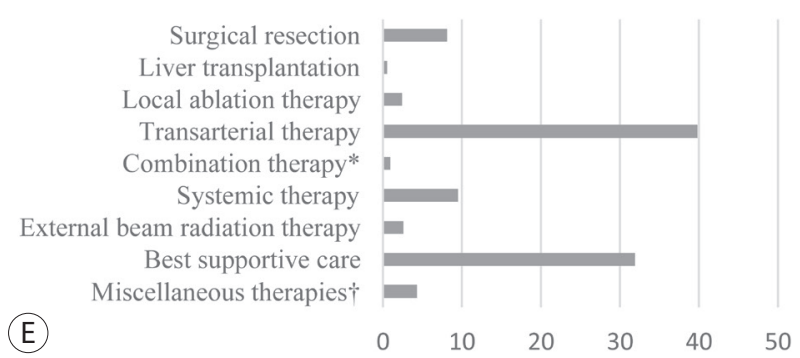

BCLC Stage 0

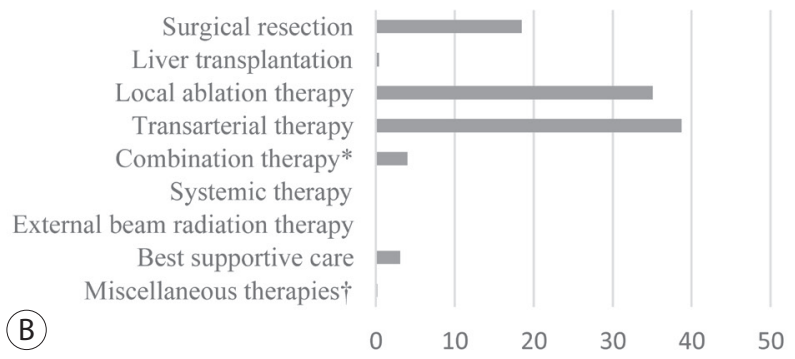

BCLC Stage B

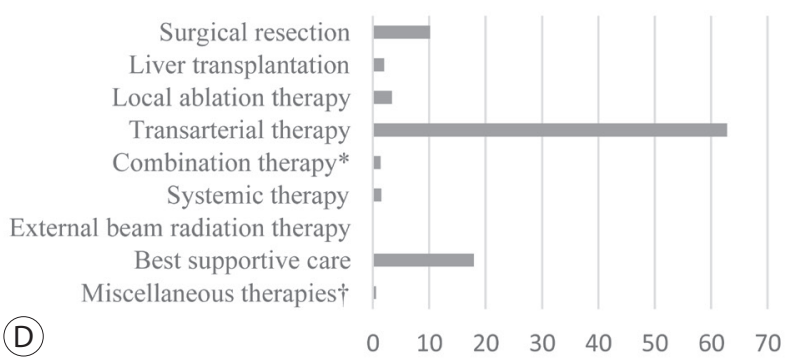

BCLC Stage D

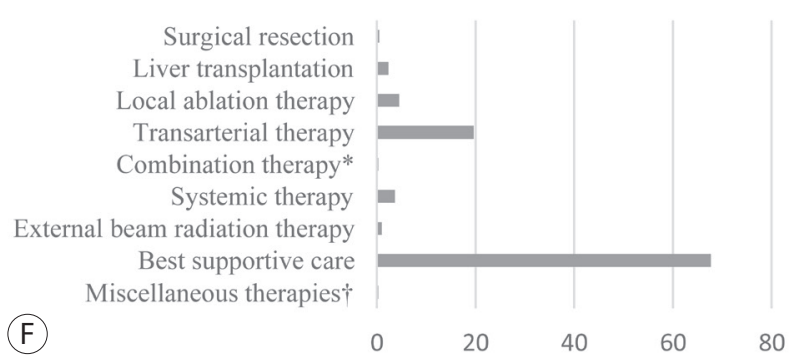

Figure 1. The initial treatment modality of the study population (A) and subgroups according to the Barcelona Clinic Liver Cancer (BCLC) stage 0 $(B)$, stage $A(C)$, stage $B(D)$, stage $C(E)$, and stage $D(F)$. "Combination therapy is defined as the combined treatment of local ablation therapy and transarterial therapy; ${ }^{\dagger}$ Miscellaneous therapies are defined as unclassifiable treatment modalities (i.e., combination therapies other than transarterial therapy and local ablation therapy). 
Jun Sik Yoon, et al.

HCC in Korea: 2008-2011

Table 3. Overall survival rates (\%) of the study population according to the baseline characteristics and the initial treatment modalities

\begin{tabular}{|c|c|c|c|c|c|c|}
\hline \multirow{2}{*}{ Variable } & \multirow{2}{*}{ Value } & \multicolumn{5}{|c|}{ Year } \\
\hline & & 1 & 2 & 3 & 4 & 5 \\
\hline All case & $6,083(100)$ & 65.6 & 54.3 & 46.2 & 40.9 & 36.8 \\
\hline \multicolumn{7}{|c|}{ Age (years, $n=6,078$, missing values $=5$ ) } \\
\hline$<40$ & $187(3.1)$ & 59.9 & 50.8 & 43.9 & 40.6 & 40.1 \\
\hline $40-49$ & $982(16.2)$ & 61.7 & 51.8 & 44.8 & 40.4 & 38.7 \\
\hline $50-59$ & $1,955(32.2)$ & 68.1 & 57.7 & 50.3 & 45.6 & 41.5 \\
\hline $60-69$ & $1,696(27.9)$ & 68.6 & 57.3 & 49.1 & 43.6 & 39.1 \\
\hline$\geq 70$ & $1,258(20.77)$ & 61.8 & 47.4 & 37.5 & 30.4 & 24.3 \\
\hline \multicolumn{7}{|l|}{ Sex $(n=6,083$, missing values $=0)$} \\
\hline Male & $4,790(78.7)$ & 64.6 & 53.3 & 45.0 & 39.8 & 35.8 \\
\hline Female & $1,293(21.3)$ & 69.5 & 57.9 & 50.8 & 45.1 & 40.4 \\
\hline \multicolumn{7}{|l|}{ Ascites $(n=6,006$, missing values $=77$ ) } \\
\hline None & $4,509(75.1)$ & 76.2 & 64.4 & 55.8 & 49.9 & 45.1 \\
\hline Mild & $964(16.1)$ & 37.9 & 27.4 & 21.1 & 17.1 & 14.3 \\
\hline Moderate to severe & $533(8.9)$ & 26.6 & 18.6 & 12.2 & 9.9 & 9.0 \\
\hline \multicolumn{7}{|c|}{ Encephalopathy ( $n=6,045$, missing values=38) } \\
\hline None & $5,894(97.5)$ & 66.5 & 55.1 & 47.0 & 41.7 & 37.5 \\
\hline Mild to moderate (grade 1 or 2) & $119(2.0)$ & 37.8 & 28.6 & 20.2 & 13.4 & 11.8 \\
\hline Severe (grade 3 or 4 ) & $32(0.5)$ & 28.1 & 28.1 & 18.8 & 18.8 & 18.8 \\
\hline \multicolumn{7}{|c|}{ Serum albumin $(\mathrm{g} / \mathrm{dL}, \mathrm{n}=5,871$, missing values $=212$ ) } \\
\hline$<2.8$ & $524(8.9)$ & 35.7 & 25.2 & 19.3 & 17.0 & 15.1 \\
\hline $2.8-3.5$ & $1,730(29.5)$ & 53.0 & 40.9 & 32.1 & 25.8 & 21.3 \\
\hline$>3.5$ & $3,617(61.6)$ & 76.6 & 65.6 & 57.5 & 52.0 & 47.7 \\
\hline \multicolumn{7}{|c|}{ Serum bilirubin (mg/dL, $\mathrm{n}=5,900$, missing values $=83$ ) } \\
\hline$<2.0$ & $4,842(82.1)$ & 72.0 & 60.3 & 51.4 & 45.9 & 41.4 \\
\hline $2.0-3.0$ & $522(8.8)$ & 48.1 & 36.8 & 30.1 & 23.9 & 20.7 \\
\hline$>3.0$ & $536(9.1)$ & 28.4 & 21.5 & 18.5 & 15.1 & 13.6 \\
\hline \multicolumn{7}{|c|}{ Prothrombin time $(I N R, n=5,733$, missing values $=350)$} \\
\hline$<1.7$ & $5,599(97.7)$ & 66.8 & 55.5 & 47.3 & 41.8 & 37.5 \\
\hline $1.7-2.3$ & $99(1.7)$ & 38.4 & 28.3 & 24.2 & 20.2 & 17.2 \\
\hline$>2.3$ & $35(0.6)$ & 20.0 & 20.0 & 17.1 & 14.3 & 14.3 \\
\hline \multicolumn{7}{|c|}{ Child-Turcotte-Pugh classification ( $n=5,719$, missing values=375) } \\
\hline A & $4,063(71.2)$ & 77.3 & 66.0 & 57.0 & 51.1 & 46.4 \\
\hline B & $1,354(23.7)$ & 42.2 & 30.4 & 23.5 & 19.0 & 15.6 \\
\hline $\mathrm{C}$ & $291(5.1)$ & 20.6 & 15.1 & 11.0 & 8.9 & 8.6 \\
\hline \multicolumn{7}{|c|}{ Tumor number $(n=6,061$, missing values $=22)$} \\
\hline 1 & $3,725(61.5)$ & 75.6 & 65.4 & 57.1 & 51.7 & 47.0 \\
\hline 2 & $826(13.6)$ & 75.3 & 59.8 & 49.2 & 41.4 & 36.8 \\
\hline 3 & $247(4.1)$ & 74.5 & 55.5 & 42.1 & 32.0 & 25.1 \\
\hline 4 & $95(1.6)$ & 55.8 & 41.1 & 32.6 & 25.3 & 21.1 \\
\hline$\geq 5$ & $1,168(19.3)$ & 26.1 & 15.8 & 11.3 & 9.2 & 7.8 \\
\hline
\end{tabular}


Table 3. Continued

\begin{tabular}{|c|c|c|c|c|c|c|}
\hline \multirow{2}{*}{ Variable } & \multirow{2}{*}{ Value } & \multicolumn{5}{|c|}{ Year } \\
\hline & & 1 & 2 & 3 & 4 & 5 \\
\hline \multicolumn{7}{|c|}{ Maximal tumor diameter $(\mathrm{cm}, \mathrm{n}=6,040$, missing values $=43$ ) } \\
\hline$<2$ & $1,185(19.6)$ & 90.0 & 81.5 & 72.7 & 66.3 & 59.7 \\
\hline $2-4.9$ & 2,346 (38.8) & 83.4 & 71.9 & 61.8 & 54.4 & 48.8 \\
\hline $5-9.9$ & $1,180(19.5)$ & 52.3 & 37.2 & 28.7 & 24.1 & 22.1 \\
\hline$\geq 10$ & $1329(22.0)$ & 24.6 & 14.4 & 10.8 & 9.6 & 8.1 \\
\hline \multicolumn{7}{|c|}{ Portal vein invasion ( $n=6,083$, missing values $=0$ ) } \\
\hline None & $4,606(75.7)$ & 79.1 & 67.5 & 57.9 & 51.5 & 46.4 \\
\hline Yes & $1,477(24.3)$ & 23.6 & 13.1 & 9.6 & 7.9 & 6.7 \\
\hline \multicolumn{7}{|c|}{ Hepatic vein invasion ( $n=6,083$, missing values $=0$ ) } \\
\hline None & $5,744(94.4)$ & 68.1 & 56.7 & 48.4 & 42.8 & 38.5 \\
\hline Yes & $329(5.6)$ & 24.5 & 13.3 & 8.6 & 8.6 & 8.0 \\
\hline \multicolumn{7}{|c|}{ Bile duct invasion $(n=6,083$, missing values $=0$ ) } \\
\hline None & $5,924(97.4)$ & 66.5 & 55.1 & 46.9 & 41.5 & 37.4 \\
\hline Yes & $159(2.6)$ & 34.0 & 23.9 & 19.5 & 18.2 & 15.1 \\
\hline \multicolumn{7}{|l|}{ T classification ( $n=6,041$, missing values $=42$ ) } \\
\hline $\mathrm{T} 1$ & $860(14.2)$ & 93.3 & 86.6 & 78.0 & 72.3 & 65.5 \\
\hline $\mathrm{T} 2$ & 2,396 (39.7) & 84.0 & 73.0 & 63.4 & 56.8 & 51.7 \\
\hline T3 & $1,954(32.3)$ & 51.1 & 36.3 & 28.1 & 22.7 & 19.4 \\
\hline T4 & $831(13.8)$ & 18.7 & 9.7 & 6.4 & 5.7 & 4.8 \\
\hline \multicolumn{7}{|l|}{$N$ classification $(n=6,083$, missing values $=0$ ) } \\
\hline No & $5,652(92.9)$ & 69.2 & 57.6 & 49.1 & 43.5 & 39.1 \\
\hline N1 & $431(7.1)$ & 19.0 & 10.9 & 8.1 & 7.0 & 6.0 \\
\hline \multicolumn{7}{|l|}{ M classification ( $n=6,083$, missing values $=0$ ) } \\
\hline M0 & $5,481(90.1)$ & 71.1 & 59.3 & 50.7 & 44.9 & 40.4 \\
\hline M1 & $602(9.9)$ & 16.1 & 8.6 & 5.3 & 4.8 & 4.0 \\
\hline \multicolumn{7}{|c|}{ Distant metastasis sites $(\mathrm{n}=569$, missing values $=33$ ) } \\
\hline Bone & $93(16.3)$ & 14.0 & 3.2 & 2.2 & 1.1 & 1.1 \\
\hline Lung & $260(45.7)$ & 16.2 & 8.1 & 5.0 & 4.6 & 3.5 \\
\hline Distant lymph node & $64(11.2)$ & 15.6 & 7.8 & 6.2 & 4.7 & 4.7 \\
\hline Lung and bone & $31(5.4)$ & 6.5 & 3.2 & 0.0 & 0.0 & 0.0 \\
\hline Bone and distant lymph node & $11(1.9)$ & 36.4 & 9.1 & 9.1 & 9.1 & 9.1 \\
\hline Lung and distant lymph node & $29(5.1)$ & 3.4 & 3.0 & 0.0 & 0.0 & 0.0 \\
\hline Bone and lung and distant lymph node & $9(1.6)$ & 11.1 & 0.0 & 0.0 & 0.0 & 0.0 \\
\hline Others & $72(12.7)$ & 16.7 & 12.5 & 8.3 & 8.3 & 6.9 \\
\hline \multicolumn{7}{|c|}{ Modified UICC stage $(n=6,045$, missing values $=38$ ) } \\
\hline Stage I & $854(14.1)$ & 93.4 & 86.8 & 78.2 & 72.6 & 65.7 \\
\hline Stage II & $2,267(37.5)$ & 86.5 & 75.7 & 66.1 & 59.2 & 54.0 \\
\hline Stage III & $1,577(26.1)$ & 59.0 & 42.8 & 33.4 & 26.9 & 23.1 \\
\hline Stage IV-A & $746(12.3)$ & 24.5 & 13.4 & 9.2 & 7.8 & 6.6 \\
\hline Stage IV-B & $601(9.9)$ & 16.0 & 8.5 & 5.3 & 4.8 & 4.0 \\
\hline
\end{tabular}


Table 3. Continued

\begin{tabular}{|c|c|c|c|c|c|c|}
\hline \multirow{2}{*}{ Variable } & \multirow{2}{*}{ Value } & \multicolumn{5}{|c|}{ Year } \\
\hline & & 1 & 2 & 3 & 4 & 5 \\
\hline \multicolumn{7}{|c|}{$B C L C$ stage $(n=5,697$, missing values $=386)$} \\
\hline 0 & 489 (8.6) & 97.5 & 93.5 & 87.7 & 81.2 & 74.0 \\
\hline A & $2,259(39.7)$ & 89.2 & 78.4 & 68.5 & 61.5 & 56.0 \\
\hline B & $657(11.5)$ & 72.3 & 54.2 & 41.1 & 32.4 & 27.4 \\
\hline C & $1,919(33.7)$ & 37.9 & 25.8 & 19.6 & 17.0 & 14.6 \\
\hline D & $373(6.5)$ & 18.8 & 13.4 & 9.4 & 7.8 & 7.5 \\
\hline \multicolumn{7}{|c|}{ Initial treatment modalities ( $n=5,974$, missing values $=109$ ) } \\
\hline Surgical resection & $998(17.6)$ & 93.1 & 88.0 & 81.4 & 77.5 & 74.4 \\
\hline Liver transplantation & $55(0.9)$ & 89.1 & 83.6 & 80.0 & 78.2 & 78.2 \\
\hline Local ablation therapy & $636(10.6)$ & 94.2 & 86.5 & 78.0 & 71.4 & 65.1 \\
\hline Transarterial therapy & $2,493(41.7)$ & 72.8 & 57.0 & 45.4 & 37.8 & 32.0 \\
\hline Combination therapy* & $108(1.8)$ & 94.4 & 84.3 & 79.6 & 72.2 & 65.7 \\
\hline Systemic therapy & $224(3.7)$ & 18.8 & 9.4 & 6.2 & 5.8 & 4.5 \\
\hline External beam radiation therapy & $61(1.0)$ & 24.6 & 13.1 & 8.2 & 6.6 & 4.9 \\
\hline Best supportive care & $1,295(21.7)$ & 25.6 & 17.2 & 14.1 & 11.9 & 10.0 \\
\hline Miscellaneous therapies ${ }^{\dagger}$ & $104(1.7)$ & 45.2 & 23.1 & 12.5 & 8.7 & 5.8 \\
\hline
\end{tabular}

Values are expressed as median (interquartile range) or number (\%).

INR, international normalized ratio; UICC, Union for International Cancer Control; BCLC, Barcelona Clinic Liver Cancer.

"Combination therapy is defined as the combined treatment of local ablation therapy and transarterial therapy; ${ }^{\dagger}$ Miscellaneous therapies are defined as unclassifiable treatment modalities (i.e., combination therapies other than transarterial therapy and local ablation therapy).

\section{DISCUSSION}

The aim of this study was to investigate the baseline characteristics, treatment modalities, and OS of patients with newly diagnosed HCC in Korea. We analyzed 6,083 patients with HCC registered in the KPLCR, which is a representative group of patients with newly diagnosed HCC in Korea, between 2008 and 2011. We found that approximately half of the patients with HCC $(48.3 \%)$ were candidates for curative treatment (BCLC stage 0 or $\mathrm{A}$ ), but one-third of patients (33.8\%) had advanced HCC (BCLC stage C). Transarterial therapy $(41.7 \%)$ was the most commonly conducted initial treatment, followed by best supportive care $(21.7 \%)$, surgical resection $(16.7 \%)$, and local ablation therapy (10.6\%). The $1-, 3$-, and 5-year OS rates were 65.6\%, 46.2\%, and 36.8\%, respectively.

The nationwide surveillance program for HCC in a highrisk population (i.e., patients over 40 years of age who had chronic hepatitis B, chronic hepatitis $\mathrm{C}$, or liver cirrhosis) was started in 2003 in Korea. As a result, early detection of HCC has gradually been increasing over time. We compared the results of this study (KPLCR data between 2008 and 2011) with the KPLCR data between 2003 and 2005 (data extracted from http://www.livercancer.or.kr). The proportion of patients with mUICC stage I increased from $10.7 \%$ in the 2003-2005 period to $14.1 \%$ in the $2008-2011$ period. Moreover, $64.2 \%, 27.0 \%$, and $8.8 \%$ of patients in the 2003-2005 period were in CTP class A, B, and C, respectively, whereas $71.0 \%, 23.8 \%$, and $5.1 \%$ of patients in the $2008-2011$ period were in CTP class A, B, and C, respectively. These data indicate that the detection of patients with early TNM-stage HCC with well-preserved liver function has been increasing over time. Therefore, the 1-, 3-, and 5-year OS rates also increased from $54.8 \%, 35.0 \%$, and $26.4 \%$ in the $2003-2005$ period to $65.6 \%, 46.2 \%$, and $36.8 \%$ in the $2008-2011$ period, respectively. 

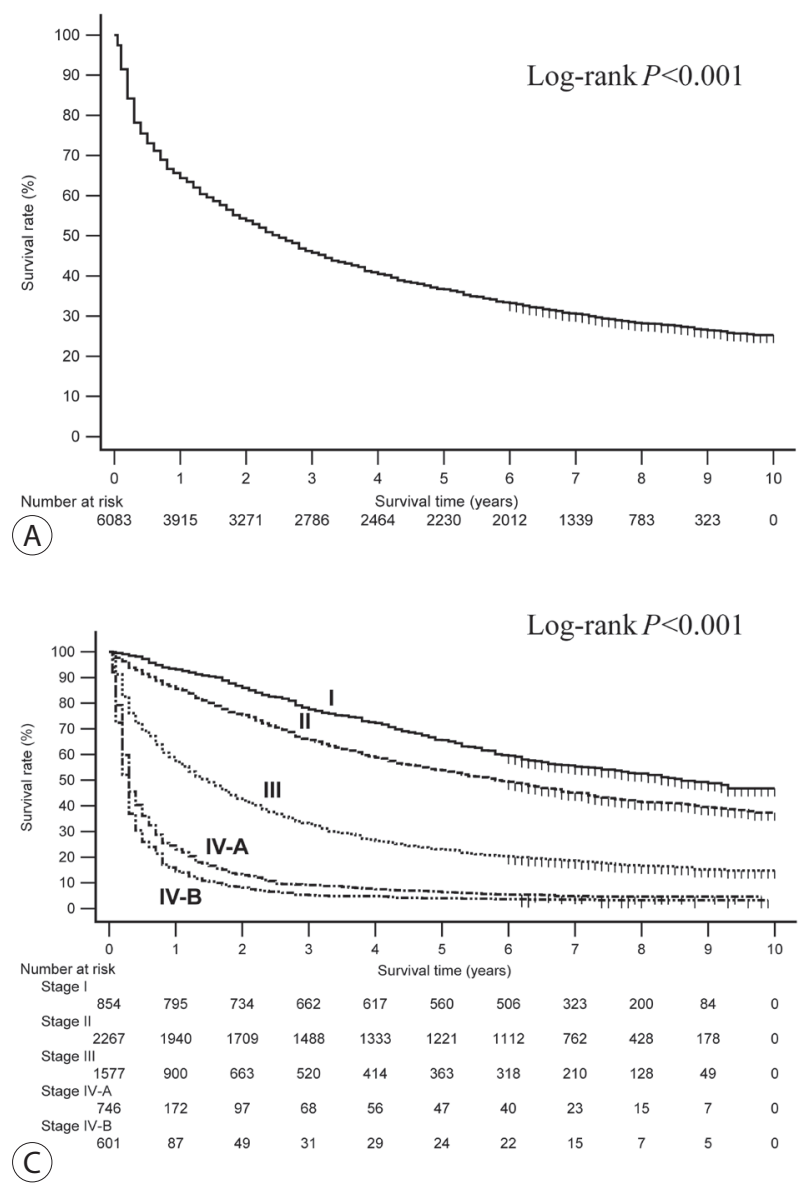

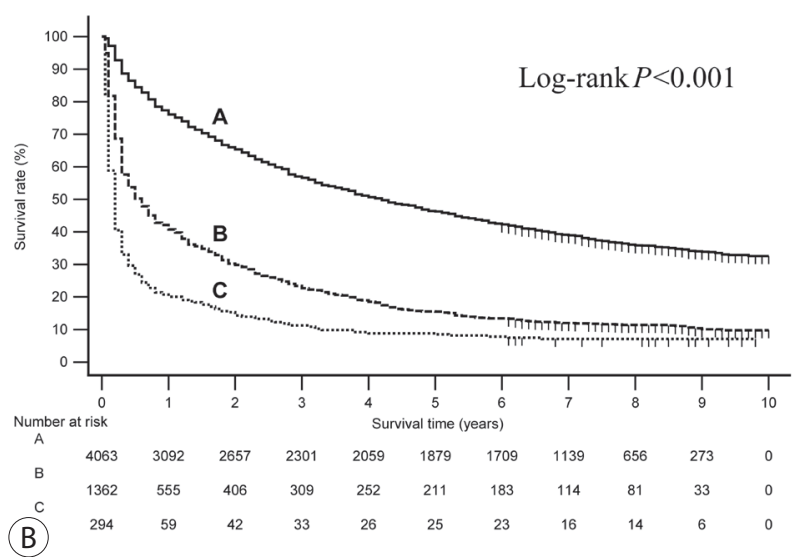

$\log -\operatorname{rank} P<0.001$

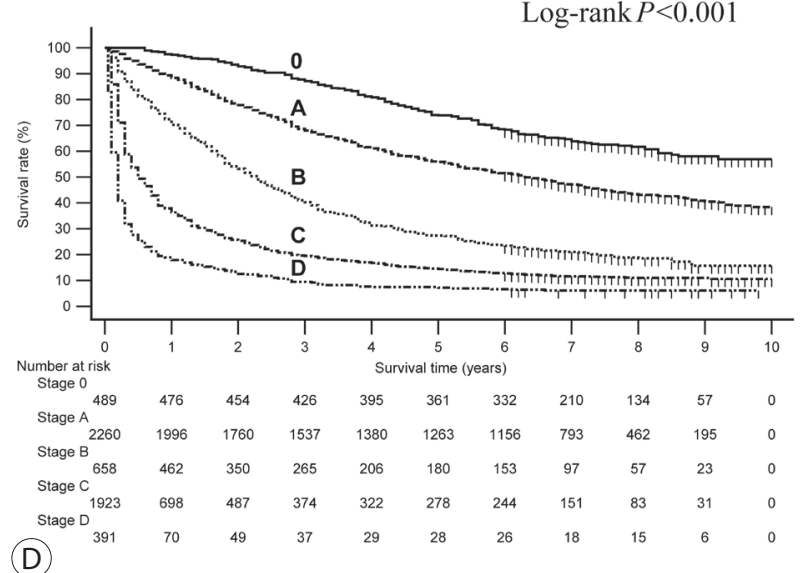

(D)

Figure 2. Overall survival curves for the study population (A) and subgroups divided by the Child-Turcotte-Pugh classes (B) and the modified Union for International Cancer Control stages (C) and the Barcelona Clinic Liver Cancer stages (D).

Approximately half of the patients with HCC (48.3\%) were candidates for curative treatment (BCLC stage 0 or A) in this study. The detection rate of BCLC stage 0 or A was higher than that in Western countries (approximately 30\%), where nationwide surveillance programs are yet to be implemented. ${ }^{17,18}$ However, the detection rate was lower than that in Japan $(62.5 \%)$ where a nationwide surveillance program began in $1980 .{ }^{19}$ Probably owing to this reason, the 5-year survival rate of Korean patients with HCC in this study (36.8\%) was higher than that in Western countries (9.6$18.0 \%),{ }^{20-22}$ but lower than that in Japan (50.8\%) during a similar study period. ${ }^{23}$ The reason patients with HCC in Korea had a lower 5-year survival rate than patients in Japan is not only because of the low detection rate of BCLC stage 0 or A ( $48.3 \%$ vs. $62.5 \%)$, but also because of the high detection rate of BCLC stage C or D (40.6\% vs. $6.0 \%) .{ }^{19}$ Intensive sur- veillance for detecting HCC at earlier stages might be required to improve the survival of patients with HCC in Korea.

In the present study, the most commonly conducted initial treatment was transarterial therapy (41.7\%), followed by best supportive care $(21.7 \%)$, surgical resection $(16.7 \%)$, and local ablation therapy (10.6\%). Transarterial therapy was the most commonly performed treatment for all HCC stages except mUICC stage IV or BCLC stage D, which was consistent with results in Western countries. ${ }^{17}$ However, the overall rate of adherence to BCLC treatment guidelines was only $37.4 \%$, which was lower than that of Western countries (58.1$70.6 \%) .{ }^{24-26}$ In particular, the adherence rates of BCLC stage 0 or A and BCLC stage C were as low as $47.4 \%$ and $9.5 \%$, respectively. Liver transplantation, one of the standard treatment modalities for BCLC stage 0 or A, was performed in 
only $0.7 \%$ of the patients with BCLC stage 0 or A stage. Moreover, approximately half of the patients in BCLC stage $\mathrm{C}$ underwent other therapies rather than the recommended systemic therapy; $39.8 \%, 8.1 \%$, and $2.4 \%$ were treated with transarterial therapy, surgical resection, and local ablation therapy, respectively. The discrepancies of the real-world treatment from the recommended treatment are thought to be caused by an extreme shortage of liver donors and the low anticipated survival benefit of systemic therapy.

In conclusion, we have shown that, between 2008 and 2011, approximately half of Korean patients newly diagnosed with HCC had BCLC stage 0 or A, but one-third of the patients had BCLC stage C. Transarterial therapy was the most commonly conducted initial treatment, and the 5-year OS was $36.8 \%$ in this period. We believe that the results described here will contribute to the clinical management of HCC and promote future study.

\section{SUPPLEMENTARY MATERIAL}

Supplementary datas can be found with this article online http://www.e-jlc.org/html/https://doi.org/10.17998/ jlc.20.1.41.

\section{ACKNOWLEDGMENTS}

This study was supported by Korean Liver Cancer Association Research Award (recipient: J. H. L). The database used in this study was provided by the Korean Central Cancer Registry, Ministry of Health and Welfare, South Korea, and the Korean Liver Cancer Association.

\section{Conflicts of Interest}

The authors declare no conflicts of interest relevant to this article.

\section{REFERENCES}

1. Statistics Korea. Annual report on the causes of death statistics 2017. Daejeon: Statistics Korea, 2018.

2. Kweon SS. Updates on cancer epidemiology in Korea, 2018. Chon- nam Med J 2018;54:90-100.

3. National Cancer Center. Korea Central Cancer Registry. Annual report of cancer statistics in Korea in 2016. Goyang: National Cancer Center, 2018.

4. McGlynn KA, Petrick JL, London WT. Global epidemiology of hepatocellular carcinoma: an emphasis on demographic and regional variability. Clin Liver Dis 2015;19:223-238.

5. European Association For The Study Of The Liver; European Organisation For Research And Treatment Of Cancer. EASL-EORTC clinical practice guidelines: management of hepatocellular carcinoma. J Hepatol 2012;56:908-943.

6. Lee YS, Seo YS, Kim JH, Lee J, Kim HR, Yoo YJ, et al. Can more aggressive treatment improve prognosis in patients with hepatocellular carcinoma? A direct comparison of the Hong Kong liver cancer and Barcelona clinic liver cancer algorithms. Gut Liver 2018;12:94101.

7. Kim BH, Lim YS, Kim EY, Kong HJ, Won YJ, Han S, et al. Temporal improvement in survival of patients with hepatocellular carcinoma in a hepatitis B virus-endemic population. J Gastroenterol Hepatol 2018:33:475-483.

8. Kwak HW, Park JW, Nam BH, Yu A, Woo SM, Kim TH, et al. Clinical outcomes of a cohort series of patients with hepatocellular carcinoma in a hepatitis B virus-endemic area. J Gastroenterol Hepatol 2014;29:820-829.

9. Korean Association for the Study of the Liver (KASL). KASL clinical practice guidelines for management of chronic hepatitis B. Clin Mol Hepatol 2019;25:93-159.

10. Lee KS, Chang HS, Lee SM, Park EC. Economic burden of cancer in Korea during 2000-2010. Cancer Res Treat 2015;47:387-398.

11. Yu SJ. A concise review of updated guidelines regarding the management of hepatocellular carcinoma around the world: 20102016. Clin Mol Hepatol 2016;22:7-17.

12. Bruix J, Sherman M; Practice Guidelines Committee, American Association for the Study of Liver Diseases. Management of hepatocellular carcinoma. Hepatology 2005;42:1208-1236.

13. 13Sheu JC, Sung JL, Chen DS, Yang PM, Lai MY, Lee CS, et al. Growth rate of asymptomatic hepatocellular carcinoma and its clinical implications. Gastroenterology 1985;89:259-266.

14. Kudo M, Kitano M, Sakurai T, Nishida N. General Rules for the Clinical and Pathological Study of Primary Liver Cancer, Nationwide Follow-Up Survey and Clinical Practice Guidelines: the outstanding achievements of the Liver Cancer Study Group of Japan. Dig Dis 2015; 33: 765-770.

15. Ueno S, Tanabe G, Nuruki K, Hamanoue M, Komorizono $Y$, Oketani $M$, et al. Prognostic performance of the new classification of primary liver cancer of Japan (4th edition) for patients with hepatocellular carcinoma: a validation analysis. Hepatol Res 2002;24:395-403. 
16. Llovet JM, Brú C, Bruix J. Prognosis of hepatocellular carcinoma: the BCLC staging classification. Semin Liver Dis 1999;19:329-338.

17. Park JW, Chen M, Colombo M, Roberts LR, Schwartz M, Chen PJ, et al. Global patterns of hepatocellular carcinoma management from diagnosis to death: the BRIDGE Study. Liver Int 2015;35:21552166.

18. El-Serag HB, Davila JA. Surveillance for hepatocellular carcinoma: in whom and how? Therap Adv Gastroenterol 2011;4:5-10.

19. Kudo M. Japan's successful model of nationwide hepatocellular carcinoma surveillance highlighting the urgent need for global surveillance. Liver Cancer 2012;1:141-143.

20. Goutté N, Sogni P, Bendersky N, Barbare JC, Falissard B, Farges 0 . Geographical variations in incidence, management and survival of hepatocellular carcinoma in a Western country. J Hepatol 2017;66:537-544.

21. Altekruse SF, McGlynn KA, Dickie LA, Kleiner DE. Hepatocellular carcinoma confirmation, treatment, and survival in surveillance, epidemiology, and end results registries, 1992-2008. Hepatology
2012; 55:476-482.

22. El-Serag HB. Hepatocellular carcinoma. N Engl J Med 2011;365:1118-1127.

23. Kudo M, Izumi N, Kubo S, Kokudo N, Sakamoto M, Shiina S, et al. Report of the 20th Nationwide Follow-up Survey of Primary Liver Cancer in Japan. Hepatol Res 2020;50:15-46.

24. Guarino M, Tortora R, de Stefano G, Coppola C, Morisco F, Salomone Megna A, et al. Adherence to Barcelona Clinic Liver Cancer guidelines in field practice: results of Progetto Epatocarcinoma Campania. J Gastroenterol Hepatol 2018;33:1123-1130.

25. Leoni S, Piscaglia F, Serio I, Terzi E, Pettinari I, Croci L, et al. Adherence to AASLD guidelines for the treatment of hepatocellular carcinoma in clinical practice: experience of the Bologna Liver Oncology Group. Dig Liver Dis 2014;46:549-555.

26. Radu P, Groza I, Iancu C, Al Hajjar N, Andreica V, Sparchez Z. Treatment of hepatocellular carcinoma in a tertiary Romanian center. Deviations from BCLC recommendations and influence on survival rate. J Gastrointestin Liver Dis 2013;22:291-297. 
Jun Sik Yoon, et al.

HCC in Korea: 2008-2011

Supplementary Table 1. Adherence rates of the BCLC treatment guideline in each Barcelona Clinic Liver Cancer stage and total study population

\begin{tabular}{lc}
\hline BCLC stage & Value \\
\hline O or A & $1,277 / 2,695(47.4)$ \\
\hline B & $407 / 648(62.8)$ \\
C & $180 / 1,899(9.5)$ \\
D & $258 / 381(67.7)$ \\
Total & $2,122 / 5,623(37.7)$ \\
\hline
\end{tabular}

Values are presented as number (\%).

BCLC, Barcelona Clinic Liver Cancer. 
Supplementary Table 2. Baseline characteristics of the patients treated with surgical therapies $(n=1,053)$

\begin{tabular}{|c|c|c|}
\hline Variable & Surgical resection $(n=998,16.7 \%)$ & Liver transplantation $(n=55,0.9 \%)$ \\
\hline \multicolumn{3}{|l|}{ Demographic variable } \\
\hline Age (years) & $56.0(49.0-64.0)$ & $52.0(47.0-58.5)$ \\
\hline Sex (male) & $792(79.4)$ & $45(81.8)$ \\
\hline Diabetes & $196(19.6)$ & $8(14.5)$ \\
\hline Hypertension & $312(31.7)$ & $5(9.3)$ \\
\hline Body mass index $\left(\mathrm{kg} / \mathrm{m}^{2}\right)$ & $23.7(21.9-25.8)$ & $24.8(22.4-27.4)$ \\
\hline Smoking & $428(43.4)$ & $25(46.3)$ \\
\hline Etiology & $n=879$ & $n=52$ \\
\hline $\mathrm{HBV}^{*}$ & $710(80.8)$ & $46(88.5)$ \\
\hline $\mathrm{HCV}$ & $64(7.3)$ & $4(7.7)$ \\
\hline Alcohol & $87(9.9)$ & $2(3.8)$ \\
\hline Others & $18(2.0)$ & 0 \\
\hline Performance status $^{\dagger}$ & $n=782$ & $n=41$ \\
\hline 0 & $705(90.2)$ & $30(73.2)$ \\
\hline 1 & $72(9.2)$ & $6(14.6)$ \\
\hline 2 & $4(0.5)$ & $3(7.3)$ \\
\hline 3 & $1(0.1)$ & 0 \\
\hline 4 & 0 & $2(4.9)$ \\
\hline Ascites & $n=998$ & $n=55$ \\
\hline None & $957(95.9)$ & $37(67.3)$ \\
\hline Mild & $37(3.7)$ & $9(16.4)$ \\
\hline Moderate to severe & $4(0.4)$ & $9(16.4)$ \\
\hline Encephalopathy & $n=991$ & $\mathrm{n}=55$ \\
\hline None & $988(99.7)$ & $51(92.7)$ \\
\hline Mild to moderate (grade 1 or 2) & $2(0.2)$ & $4(7.3)$ \\
\hline Severe (grade 3 or 4) & $1(0.1)$ & 0 \\
\hline \multicolumn{3}{|l|}{ Laboratory variable } \\
\hline Total bilirubin (mg/dL) & $0.8(0.6-1.0)$ & $1.5(0.9-2.9)$ \\
\hline Serum albumin (g/dL) & $4.2(3.8-4.4)$ & $3.1(2.8-3.6)$ \\
\hline Alanine aminotransferase (IU/L) & $33.0(22.0-48.0)$ & $33.0(26.0-42.0)$ \\
\hline Platelet count $\left(10^{9} / \mathrm{L}\right)$ & $163.0(124.0-208.0)$ & $74.0(53.0-112.0)$ \\
\hline Prothrombin time (INR) & $1.05(1.00-1.11)$ & $1.31(1.15-1.54)$ \\
\hline Creatinine (mg/dL) & $0.90(0.80-1.00)$ & $0.90(0.76-1.00)$ \\
\hline Sodium (mmol/L) & $140.0(138.0-142.0)$ & $138.0(135.0-140.5)$ \\
\hline Glucose (mg/dL) & $105.0(93.5-127.0)$ & $104.0(90.0-133.5)$ \\
\hline Total Cholesterol (mg/dL) & $164.0(142.0-185.0)$ & $140.0(116.0-159.0)$ \\
\hline Alpha-fetoprotein (ng/mL) & $28.3(5.4-304.3)$ & $17.2(6.5-106.4)$ \\
\hline PIVKA-II (mAU/mL) & $79.5(29.0-500.0)$ & 31.5 (16.0-194.0) \\
\hline
\end{tabular}


Supplementary Table 2. Continued

\begin{tabular}{|c|c|c|}
\hline Variable & Surgical resection $(n=998,16.7 \%)$ & Liver transplantation $(n=55,0.9 \%)$ \\
\hline Child-Turcotte-Pugh class & $n=963$ & $n=52$ \\
\hline A & $919(95.4)$ & $24(46.2)$ \\
\hline B & $43(4.5)$ & $20(38.5)$ \\
\hline C & $1(0.1)$ & $8(15.4)$ \\
\hline MELD score & $7.4(6.8-8.6)$ & $11.2(8.4-15.4)$ \\
\hline MELD-Na score & $8.1(7.1-9.8)$ & $14.1(9.6-19.2)$ \\
\hline \multicolumn{3}{|l|}{ Tumor variable } \\
\hline Tumor number & $\mathrm{n}=988$ & $n=53$ \\
\hline 1 & 849 (85.9) & $26(49.1)$ \\
\hline 2 & $112(11.3)$ & $11(20.8)$ \\
\hline 3 & $13(1.3)$ & $4(7.5)$ \\
\hline 4 & $3(0.3)$ & $1(1.9)$ \\
\hline$\geq 5$ & $11(1.1)$ & $11(20.8)$ \\
\hline Maximal tumor diameter (cm) & $3.2(2.2-5.0)$ & $2.5(1.5-4.0)$ \\
\hline Portal vein invasion & $60(6.0)$ & $7(12.7)$ \\
\hline Hepatic vein invasion & $14(1.4)$ & 0 \\
\hline Bile duct invasion & $14(1.4)$ & 0 \\
\hline Lymph node metastasis & $14(1.4)$ & 0 \\
\hline Distant metastasis & $14(1.4)$ & 0 \\
\hline Modified UICC stage & $n=988$ & $n=53$ \\
\hline Stage I & $120(12.1)$ & $6(11.3)$ \\
\hline Stage II & $674(68.2)$ & 23 (43.4) \\
\hline Stage III & $155(15.7)$ & $22(41.5)$ \\
\hline Stage IV-A & $25(2.5)$ & $2(3.8)$ \\
\hline Stage IV-B & $14(1.4)$ & 0 \\
\hline BCLC stage & $n=956$ & $n=51$ \\
\hline 0 & $89(9.3)$ & $2(3.9)$ \\
\hline A & $646(67.6)$ & 17 (33.3) \\
\hline B & $66(6.9)$ & $13(25.5)$ \\
\hline C & $153(16.0)$ & $10(19.6)$ \\
\hline$D$ & $2(0.2)$ & $9(17.6)$ \\
\hline
\end{tabular}

Values are expressed as median (interquartile range) or number (\%).

HBV, hepatitis B virus; HCV, hepatitis C virus; INR, international normalized ratio; PIVKA-II, protein induced by vitamin K absence-II; MELD, Model for End Stage Liver Disease; UICC, Union for International Cancer Control; BCLC, Barcelona Clinic Liver Cancer.

"Patients co-infected with HBV and HCV were also included; ${ }^{\dagger}$ Performance status was defined as follows: 0, fully active without symptoms; 1 , ambulatory with symptoms; 2 , bedridden $<50 \%$ of the time; 3 , bedridden $>50 \%$ of the time but capable of self-care; 4 , bedridden $100 \%$ of the time and incapable of self-care. 
Supplementary Table 3. Baseline characteristics of the patients treated with locoregional therapies $(n=3,237)$

\begin{tabular}{|c|c|c|c|}
\hline Variable & $\begin{array}{l}\text { Local ablation therapy } \\
\qquad(n=636,10.6 \%)\end{array}$ & $\begin{array}{l}\text { Transarterial therapy } \\
(n=2,493,41.7 \%)\end{array}$ & $\begin{array}{l}\text { Combination therapy } \\
\qquad(n=108,1.8 \%)\end{array}$ \\
\hline \multicolumn{4}{|l|}{ Demographic variable } \\
\hline Age (years) & $60.0(52.0-68.0)$ & $60.0(52.0-68.0)$ & $60.0(52.5-67.0)$ \\
\hline Sex (male) & $462(72.6)$ & $1,968(78.9)$ & $80(74.1)$ \\
\hline Diabetes & $161(25.3)$ & $621(24.9)$ & $34(31.5)$ \\
\hline Hypertension & $187(29.6)$ & $798(32.4)$ & $39(36.1)$ \\
\hline Body mass index $\left(\mathrm{kg} / \mathrm{m}^{2}\right)$ & $24.3(22.2-26.2)$ & $23.7(21.8-26.0)$ & $24.2(22.4-26.7)$ \\
\hline Smoking & $238(37.7)$ & $1,148(46.4)$ & $45(41.7)$ \\
\hline Etiology & $n=574$ & $n=2,207$ & $n=86$ \\
\hline $\mathrm{HBV}^{\dagger}$ & $387(67.4)$ & $1,558(70.6)$ & $65(75.6)$ \\
\hline $\mathrm{HCV}$ & $96(16.7)$ & $287(13.0)$ & $9(10.5)$ \\
\hline Alcohol & $71(12.4)$ & $302(13.7)$ & $10(11.6)$ \\
\hline Others & $20(3.5)$ & $60(2.7)$ & $2(2.3)$ \\
\hline Performance status $^{\ddagger}$ & $n=418$ & $n=1,728$ & $n=81$ \\
\hline 0 & $384(91.9)$ & $1,421(82.2)$ & $75(92.6)$ \\
\hline 1 & $26(6.2)$ & $245(14.2)$ & $5(6.2)$ \\
\hline 2 & $6(1.4)$ & $44(2.5)$ & $1(1.2)$ \\
\hline 3 & $2(0.5)$ & $11(0.6)$ & 0 \\
\hline 4 & 0 & $7(0.4)$ & 0 \\
\hline Ascites & $n=636$ & $n=2,493$ & $n=108$ \\
\hline None & $553(86.9)$ & $1,961(78.7)$ & $94(87.0)$ \\
\hline Mild & $58(9.1)$ & $364(14.6)$ & $13(12.0)$ \\
\hline Moderate to severe & $25(3.9)$ & $168(6.7)$ & $1(0.9)$ \\
\hline Encephalopathy & $n=633$ & $n=2,479$ & $n=108$ \\
\hline None & $624(98.6)$ & $2,435(98.2)$ & $107(99.1)$ \\
\hline Mild to moderate (grade 1 or 2) & $5(0.8)$ & $33(1.3)$ & $1(0.9)$ \\
\hline Severe (grade 3 or 4) & $4(0.6)$ & $11(0.4)$ & 0 \\
\hline \multicolumn{4}{|l|}{ Laboratory variable } \\
\hline Total bilirubin (mg/dL) & $0.9(0.7-1.4)$ & $1.0(0.7-1.5)$ & $0.8(0.5-1.3)$ \\
\hline Serum albumin (g/dL) & $3.9(3.4-4.2)$ & $3.7(3.3-4.1)$ & $3.9(3.4-4.2)$ \\
\hline Alanine aminotransferase (IU/L) & $34.0(22.0-52.0)$ & $37.0(24.0-58.0)$ & $33.0(22.0-48.5)$ \\
\hline Platelet count $\left(10^{9} / \mathrm{L}\right)$ & $110.0(75.5-152.0)$ & $126.0(86.0-185.0)$ & $111.0(77.0-134.5)$ \\
\hline Prothrombin time (INR) & $1.12(1.05-1.23)$ & $1.11(1.04-1.23)$ & $1.12(1.06-1.19)$ \\
\hline Creatinine (mg/dL) & $0.90(0.72-1.00)$ & $0.90(0.73-1.00)$ & $0.90(0.79-1.08)$ \\
\hline Sodium (mmol/L) & $140.0(138.0-142.0)$ & $139.0(137.0-141.0)$ & $139.8(138.0-142.0)$ \\
\hline Glucose (mg/dL) & $108.0(94.0-142.0)$ & $110.0(94.0-143.0)$ & $116.0(98.5-138.5)$ \\
\hline Total cholesterol (mg/dL) & $155.5(133.5-173.0)$ & $152.0(128.0-178.0)$ & $149.0(131.0-179.0)$ \\
\hline Alpha-fetoprotein (ng/mL) & $12.3(4.9-49.6)$ & $43.3(8.2-567.3)$ & $12.1(6.1-49.5)$ \\
\hline PIVKA-II (mAU/mL) & $28.0(18.5-56.5)$ & $151.0(29.5-1,200.0)$ & $32.5(16.0-89.0)$ \\
\hline
\end{tabular}


Supplementary Table 3. Continued

\begin{tabular}{|c|c|c|c|}
\hline Variable & $\begin{array}{l}\text { Local ablation therapy } \\
\qquad(n=636,10.6 \%)\end{array}$ & $\begin{array}{l}\text { Transarterial therapy } \\
\qquad(n=2,493,41.7 \%)\end{array}$ & $\begin{array}{c}\text { Combination therapy } \\
(n=108,1.8 \%)\end{array}$ \\
\hline Child-Turcotte-Pugh class & $n=608$ & $\mathrm{n}=2,353$ & $\mathrm{n}=99$ \\
\hline A & $491(80.8)$ & $1,767(75.1)$ & $78(78.8)$ \\
\hline B & $101(16.6)$ & $530(22.5)$ & $20(20.2)$ \\
\hline C & $16(2.6)$ & $56(2.4)$ & $1(1.0)$ \\
\hline MELD score & $8.6(7.3-10.6)$ & $8.6(7.3-10.8)$ & $8.5(7.2-9.9)$ \\
\hline MELD-Na score & $9.4(7.7-12.2)$ & $10.0(8.1-13.1)$ & $9.3(7.7-11.5)$ \\
\hline \multicolumn{4}{|l|}{ Tumor variable } \\
\hline Tumor number & $n=636$ & $n=2,490$ & $n=107$ \\
\hline 1 & $537(84.4)$ & $1,417(56.9)$ & $72(67.3)$ \\
\hline 2 & $81(12.7)$ & $409(16.4)$ & $23(21.5)$ \\
\hline 3 & $9(1.4)$ & $165(6.6)$ & $5(4.7)$ \\
\hline 4 & 0 & $60(2.4)$ & $1(0.9)$ \\
\hline$\geq 5$ & $9(1.4)$ & 439 (17.6) & $6(5.6)$ \\
\hline Maximal tumor diameter $(\mathrm{cm})$ & $1.9(1.5-2.5)$ & $3.0(2.0-5.0)$ & $2.0(1.5-2.9)$ \\
\hline Portal vein invasion & $15(2.4)$ & $483(19.4)$ & $14(13.0)$ \\
\hline Hepatic vein invasion & $1(0.2)$ & $98(3.9)$ & $2(1.9)$ \\
\hline Bile duct invasion & 0 & $48(1.9)$ & 0 \\
\hline Lymph node metastasis & $5(0.8)$ & $127(5.1)$ & $2(1.9)$ \\
\hline Distant metastasis & $6(0.9)$ & $148(5.9)$ & $2(1.9)$ \\
\hline Modified UICC stage & $n=633$ & $n=2,484$ & $\mathrm{n}=107$ \\
\hline Stage I & $281(44.4)$ & $326(13.1)$ & $32(29.9)$ \\
\hline Stage II & $280(44.2)$ & $937(37.7)$ & $45(42.1)$ \\
\hline Stage III & $62(9.8)$ & $787(31.7)$ & $21(19.6)$ \\
\hline Stage IV-A & $4(0.6)$ & 287 (11.6) & $7(6.5)$ \\
\hline Stage IV-B & $6(0.9)$ & $147(5.9)$ & $2(1.9)$ \\
\hline BCLC stage & $n=608$ & $n=2,352$ & $n=99$ \\
\hline 0 & $169(27.8)$ & $186(7.9)$ & $19(19.2)$ \\
\hline A & $354(58.2)$ & $939(39.9)$ & $52(52.5)$ \\
\hline B & $22(3.6)$ & $406(17.3)$ & $9(9.1)$ \\
\hline C & $46(7.6)$ & $753(32.0)$ & 18 (18.2) \\
\hline D & $17(2.8)$ & $68(2.9)$ & $1(1.0)$ \\
\hline
\end{tabular}

Values are expressed as median (interquartile range) or number (\%).

HBV, hepatitis B virus; HCV, hepatitis C virus; INR, international normalized ratio; PIVKA-II, protein induced by vitamin K absence-II; MELD, Model for End Stage Liver Disease; UICC, Union for International Cancer Control; BCLC, Barcelona Clinic Liver Cancer.

"Combination therapy is defined as the combined treatment of local ablation therapy and transarterial therapy; ${ }^{\dagger}$ Patients co-infected with HBV

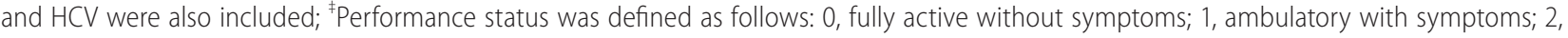
bedridden $<50 \%$ of the time; 3 , bedridden $>50 \%$ of the time but capable of self-care; 4 , bedridden $100 \%$ of the time and incapable of self-care. 
Supplementary Table 4. Baseline characteristics of the patients treated with systemic therapy, external beam radiation therapy, best supportive care, and miscellaneous therapies $(n=1,684)$

\begin{tabular}{|c|c|c|c|c|}
\hline Variable & $\begin{array}{l}\text { Systemic therapy } \\
(\mathrm{n}=224,3.7 \%)\end{array}$ & $\begin{array}{l}\text { External beam radiation } \\
\text { therapy }(n=61,1.1 \%)\end{array}$ & $\begin{array}{l}\text { Best supportive care } \\
\qquad(n=1,295,21.7 \%)\end{array}$ & $\begin{array}{l}\text { Miscellaneous therapies }{ }^{*} \\
\qquad(\mathrm{n}=104,1.7 \%)\end{array}$ \\
\hline \multicolumn{5}{|l|}{ Demographic variable } \\
\hline Age (years) & $54.0(47.5-64.0)$ & $55.0(47.0-64.0)$ & $61.5(52.5-71.0)$ & $53.2(48.0-57.0)$ \\
\hline Sex (male) & $189(84.4)$ & $48(78.7)$ & $1,030(79.5)$ & 89 (85.6) \\
\hline Diabetes & 35 (15.6) & 8 (13.1) & $302(23.3)$ & $11(10.6)$ \\
\hline Hypertension & 44 (19.8) & $10(17.2)$ & $366(29.9)$ & $23(22.1)$ \\
\hline Body mass index $\left(\mathrm{kg} / \mathrm{m}^{2}\right)$ & $23.1(21.3-24.9)$ & $22.9(20.9-25.4)$ & $23.6(21.5-26.1)$ & $23.3(21.2-25.0)$ \\
\hline Smoking & $111(50.2)$ & $29(48.3)$ & $535(43.7)$ & $57(54.8)$ \\
\hline Etiology & $n=205$ & $\mathrm{n}=55$ & $n=1,037$ & $\mathrm{n}=99$ \\
\hline $\mathrm{HBV}^{\dagger}$ & $158(77.1)$ & $47(85.5)$ & $694(66.9)$ & $84(84.8)$ \\
\hline $\mathrm{HCV}$ & $15(7.3)$ & $3(5.5)$ & $132(12.7)$ & $9(9.1)$ \\
\hline Alcohol & $22(10.7)$ & $5(9.1)$ & $192(18.5)$ & $4(4.0)$ \\
\hline Others & $10(4.9)$ & 0 & $19(1.8)$ & $2(2.0)$ \\
\hline Performance status $^{\ddagger}$ & $n=164$ & $n=38$ & $n=772$ & $n=80$ \\
\hline 0 & $98(59.8)$ & $23(60.5)$ & $403(52.2)$ & $51(63.8)$ \\
\hline 1 & $53(32.3)$ & $10(26.3)$ & $187(24.2)$ & $25(31.2)$ \\
\hline 2 & $6(3.7)$ & $2(5.3)$ & $89(11.5)$ & $4(5.0)$ \\
\hline 3 & $2(1.2)$ & $2(5.3)$ & $53(6.9)$ & 0 \\
\hline 4 & $5(3.0)$ & $1(2.6)$ & $40(5.2)$ & 0 \\
\hline Ascites & $n=224$ & $n=61$ & $n=1,295$ & $n=104$ \\
\hline None & $129(57.6)$ & $35(57.4)$ & $666(51.4)$ & $76(73.1)$ \\
\hline Mild & $63(28.1)$ & $20(32.8)$ & $357(27.6)$ & $25(24.0)$ \\
\hline Moderate to severe & $32(14.3)$ & $6(9.8)$ & $272(21.0)$ & $3(2.9)$ \\
\hline Encephalopathy & $n=221$ & $n=61$ & $n=1,286$ & $n=103$ \\
\hline None & $213(96.4)$ & $57(93.4)$ & $1,218(94.7)$ & $102(99.0)$ \\
\hline Mild to moderate (grade 1 or 2) & $8(3.6)$ & $4(6.6)$ & $52(4.0)$ & $1(1.0)$ \\
\hline Severe (grade 3 or 4) & 0 & 0 & $16(1.2)$ & 0 \\
\hline \multicolumn{5}{|l|}{ Laboratory variable } \\
\hline Total bilirubin (mg/dL) & $1.1(0.8-1.7)$ & $1.2(0.8-1.9)$ & $3.4(0.8-3.3)$ & $1.3(0.6-1.2)$ \\
\hline Serum albumin (g/dL) & $3.6(3.2-4.0)$ & $3.6(3.0-3.9)$ & $3.3(2.8-3.7)$ & $3.8(3.4-4.2)$ \\
\hline Alanine aminotransferase (IU/L) & $46.0(30.0-75.0)$ & $49.0(34.0-83.0)$ & $67.0(24.5-85.0)$ & $80.4(22.0-78.6)$ \\
\hline Platelet count $\left(10^{9} / \mathrm{L}\right)$ & $171.0(123.0-244.0)$ & $142.5(112.0-204.0)$ & $165.8(86.5-218.0)$ & $174.4(104.0-221.0)$ \\
\hline Prothrombin time (INR) & $1.12(1.03-1.19)$ & $1.15(1.07-1.29)$ & $1.23(1.06-1.33)$ & $1.10(1.02-1.16)$ \\
\hline Creatinine (mg/dL) & $0.90(0.71-1.00)$ & $0.80(0.70-0.94)$ & $0.97(0.70-1.10)$ & $0.80(0.69-0.94)$ \\
\hline Sodium (mmol/L) & $138.0(135.0-140.0)$ & $138.0(134.0-140.0)$ & $136.0(134.0-140.0)$ & $138.6(137.0-140.0)$ \\
\hline Glucose (mg/dL) & $106.5(93.0-134.0)$ & $116.0(95.0-129.5)$ & $143.3(95.5-161.0)$ & $114.4(90.0-123.0)$ \\
\hline Total cholesterol (mg/dL) & $164.5(136.0-196.0)$ & $165.0(122.0-200.0)$ & $156.1(118.5-185.5)$ & $163.4(136.0-187.0)$ \\
\hline Alpha-fetoprotein (ng/mL) & 1,750.0 (84.3-19,982.2) & $726.0(33.1-8,592.2)$ & $11,658.3(8.2-3,482.2)$ & $12,250.7(21.3-24,235.3)$ \\
\hline PIVKA-II (mAU/mL) & $2,000.0(818.0-2,000.0)$ & $685.0(88.5-2,000.0)$ & $1,814.0(83.5-2,000.0)$ & $2,730.0(292.0-2,000.0)$ \\
\hline
\end{tabular}


Supplementary Table 4. Continued

\begin{tabular}{|c|c|c|c|c|}
\hline Variable & $\begin{array}{l}\text { Systemic therapy } \\
(n=224,3.7 \%)\end{array}$ & $\begin{array}{l}\text { External beam radiation } \\
\text { therapy }(n=61,1.1 \%)\end{array}$ & $\begin{array}{c}\text { Best supportive care } \\
(n=1,295,21.7 \%)\end{array}$ & $\begin{array}{l}\text { Miscellaneous therapies } \\
\qquad(\mathrm{n}=104,1.7 \%)\end{array}$ \\
\hline Child-Turcotte-Pugh class & $n=212$ & $\mathrm{n}=58$ & $n=1,169$ & $\mathrm{n}=98$ \\
\hline A & $129(60.8)$ & $27(46.6)$ & $491(37.9)$ & $78(79.6)$ \\
\hline B & $75(35.4)$ & $30(51.7)$ & $485(37.5)$ & $19(19.4)$ \\
\hline C & $8(3.8)$ & $1(1.7)$ & $193(14.9)$ & $1(1.0)$ \\
\hline MELD score & $8.9(7.5-10.9)$ & $9.7(7.8-11.3)$ & $12.0(8.2-14.5)$ & $8.5(7.0-9.8)$ \\
\hline MELD-Na score & $11.3(8.9-14.1)$ & $12.4(9.4-15.1)$ & $14.4(9.6-18.4)$ & $9.8(7.5-11.4)$ \\
\hline \multicolumn{5}{|l|}{ Tumor variable } \\
\hline Tumor number & $n=224$ & $n=61$ & $n=1,289$ & $n=104$ \\
\hline 1 & $74(33.0)$ & $32(52.5)$ & $598(46.4)$ & $50(48.1)$ \\
\hline 2 & $17(7.6)$ & $8(13.1)$ & $138(10.7)$ & $14(13.5)$ \\
\hline 3 & $8(3.6)$ & 0 & $30(2.3)$ & $7(6.7)$ \\
\hline 4 & $3(1.3)$ & 0 & $23(1.8)$ & $1(1.0)$ \\
\hline$\geq 5$ & $122(54.5)$ & $21(34.4)$ & $500(38.8)$ & $32(30.8)$ \\
\hline Maximal tumor diameter $(\mathrm{cm})$ & $7.0(4.8-10.0)$ & $4.2(2.5-8.0)$ & $6.0(2.9-9.0)$ & $7.1(4.6-8.8)$ \\
\hline Portal vein invasion & $150(67.0)$ & $43(70.5)$ & $621(48.0)$ & $67(64.4)$ \\
\hline Hepatic vein invasion & $43(19.2)$ & $9(14.8)$ & $155(12.0)$ & $11(10.6)$ \\
\hline Bile duct invasion & $8(3.6)$ & $6(9.8)$ & $74(5.7)$ & $7(6.7)$ \\
\hline Lymph node metastasis & 49 (21.9) & $16(26.2)$ & $192(14.8)$ & $17(16.3)$ \\
\hline Distant metastasis & $99(44.2)$ & $24(39.3)$ & $274(21.2)$ & $26(25.0)$ \\
\hline Modified UICC stage & $n=224$ & $n=61$ & $n=1,284$ & $n=103$ \\
\hline Stage I & $1(0.4)$ & $1(1.6)$ & $56(4.4)$ & $3(2.9)$ \\
\hline Stage II & $11(4.9)$ & $4(6.6)$ & $243(18.9)$ & $11(10.7)$ \\
\hline Stage III & $41(18.3)$ & $14(23.0)$ & $418(32.6)$ & $34(33.0)$ \\
\hline Stage IV-A & $72(32.1)$ & $18(29.5)$ & $293(22.8)$ & $29(28.2)$ \\
\hline Stage IV-B & $99(44.2)$ & $24(39.3)$ & $274(21.3)$ & $26(25.2)$ \\
\hline BCLC stage & $n=212$ & $n=58$ & $n=1,167$ & $n=98$ \\
\hline 0 & 0 & 0 & $15(1.3)$ & $1(1.0)$ \\
\hline A & $8(3.8)$ & $3(5.2)$ & $184(15.8)$ & $10(10.2)$ \\
\hline B & $10(4.7)$ & $1(1.7)$ & $116(9.9)$ & $4(4.1)$ \\
\hline C & $180(84.9)$ & $50(86.2)$ & $603(51.7)$ & $82(83.7)$ \\
\hline D & $14(6.6)$ & $4(6.9)$ & $249(21.3)$ & $1(1.0)$ \\
\hline
\end{tabular}

Values are expressed as median (interquartile range) or number (\%).

HBV, hepatitis B virus; HCV, hepatitis C virus; INR, international normalized ratio; HDL, high-density lipoprotein; LDL, low-density lipoprotein; PIVKA-II, protein induced by vitamin K absence-II; MELD, Model for End Stage Liver Disease; UICC, Union for International Cancer Control; BCLC, Barcelona Clinic Liver Cancer.

"Miscellaneous therapies are defined as unclassifiable treatment modalities (i.e., combination therapies other than transarterial therapy and local ablation therapy); ${ }^{\dagger}$ Patients co-infected with HBV and HCV were also included; ${ }^{\ddagger}$ Performance status was defined as follows: 0 , fully active without symptoms; 1 , ambulatory with symptoms; 2 , bedridden $<50 \%$ of the time; 3 , bedridden $>50 \%$ of the time but capable of self-care; 4 , bedridden $100 \%$ of the time and incapable of self-care. 


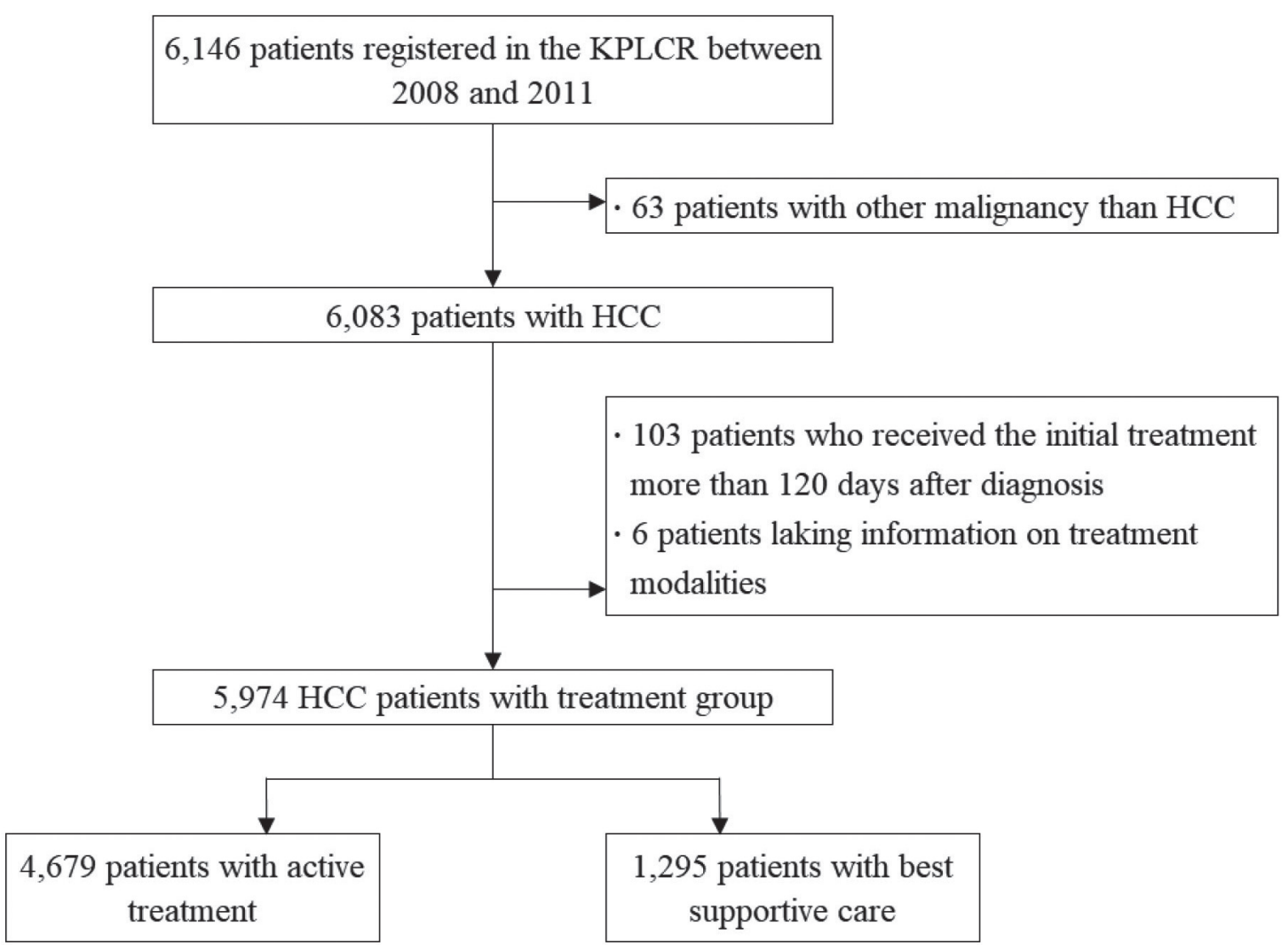

Supplementary Fig. 1. Flow diagram of the study population. KPLCR, Korean Primary Liver Cancer Registry; HCC, hepatocellular carcinoma. 

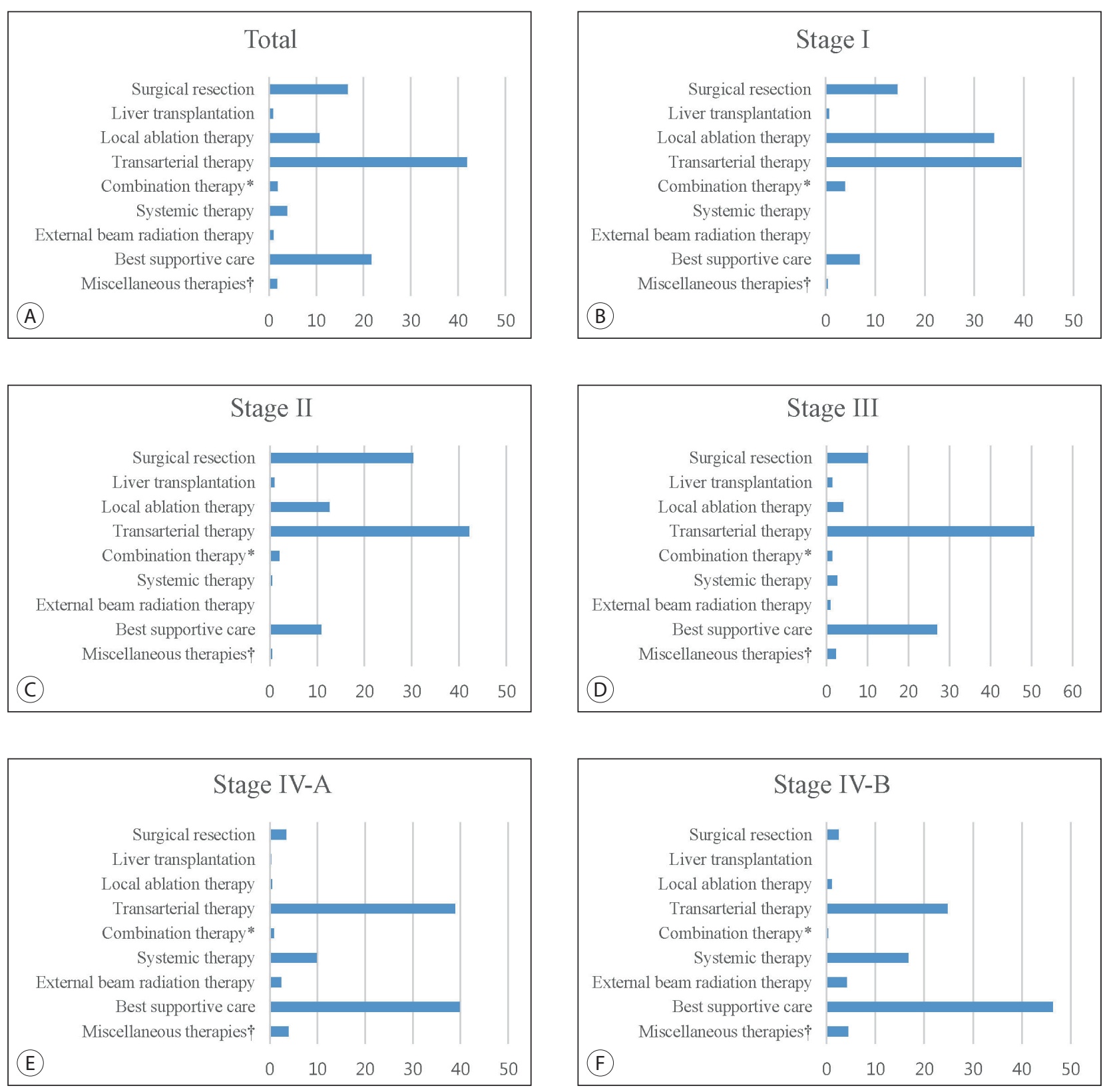

Supplementary Fig. 2. The initial treatment modality of the study population according to the modified Union for International Cancer Control staging system. "Combination therapy is defined as the combined treatment of local ablation therapy and transarterial therapy; ${ }^{\dagger}$ Miscellaneous therapies are defined as unclassifiable treatment modalities (i.e., combination therapies other than transarterial therapy and local ablation therapy). 

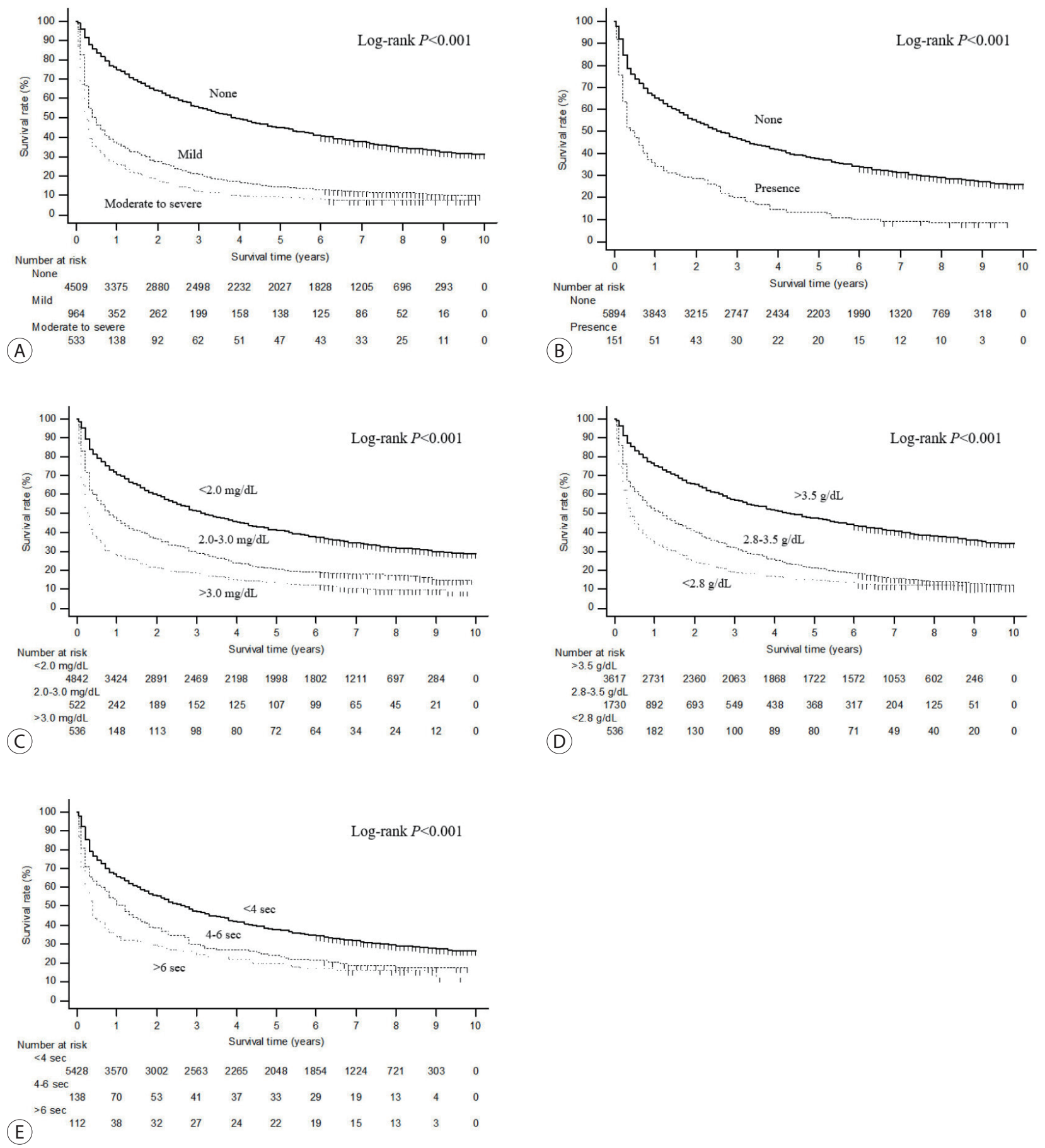

Supplementary Fig. 3. Cumulative survival curves for the subgroups according to the presence of ascites (A) and hepatic encephalopathy (B), the serum levels of bilirubin (C) and albumin (D), and prolongation (seconds) of prothrombin time (E). 